\title{
Urgent need for federal investment in research on cannabis health impacts, say researchers
}

\author{
Cite as: CMAJ 2018 February 5;190:E149-50. doi: 10.1503/cmaj.109-5554
}

Posted on cmajnews.com on Jan. 17, 2018.

W ith the deadline for legalization of nonmedical marijuana approaching, scientists studying the health impacts of cannabis are calling on the federal government to implement a comprehensive research program.

"Considerably more funding has to be made available," said Dr. Mark Ware, a pain researcher at McGill University.

At McMaster University, Dr. Suzanne Archie, who researches links between youth cannabis use and schizophrenia, said she has yet to see any appreciable upswing in federal research support. "There's been no new funding recently in our area," she said. "I've seen no calls for research."

This concern was echoed by Dr. Jürgen Rehm, a senior scientist at the Centre for Addiction and Mental Health. "I see little sign that the federal government is commissioning any serious new research into the health impacts of cannabis," he said.

In its final report, the federal Task Force on Cannabis Legalization and Regulation, cochaired by Ware, called for more federal leadership on supporting cannabis research. The task force suggested that a portion of government revenue from taxes on cannabis be used to fund the research. Tax revenue from medical marijuana has been growing for more than a decade, and the recreational market is projected to produce even greater revenues.

Historically, legal prohibitions on cannabis have inhibited research on its health impacts. But that is about to change, so "the federal government now needs to engage with its scientific granting agencies," said Ware.

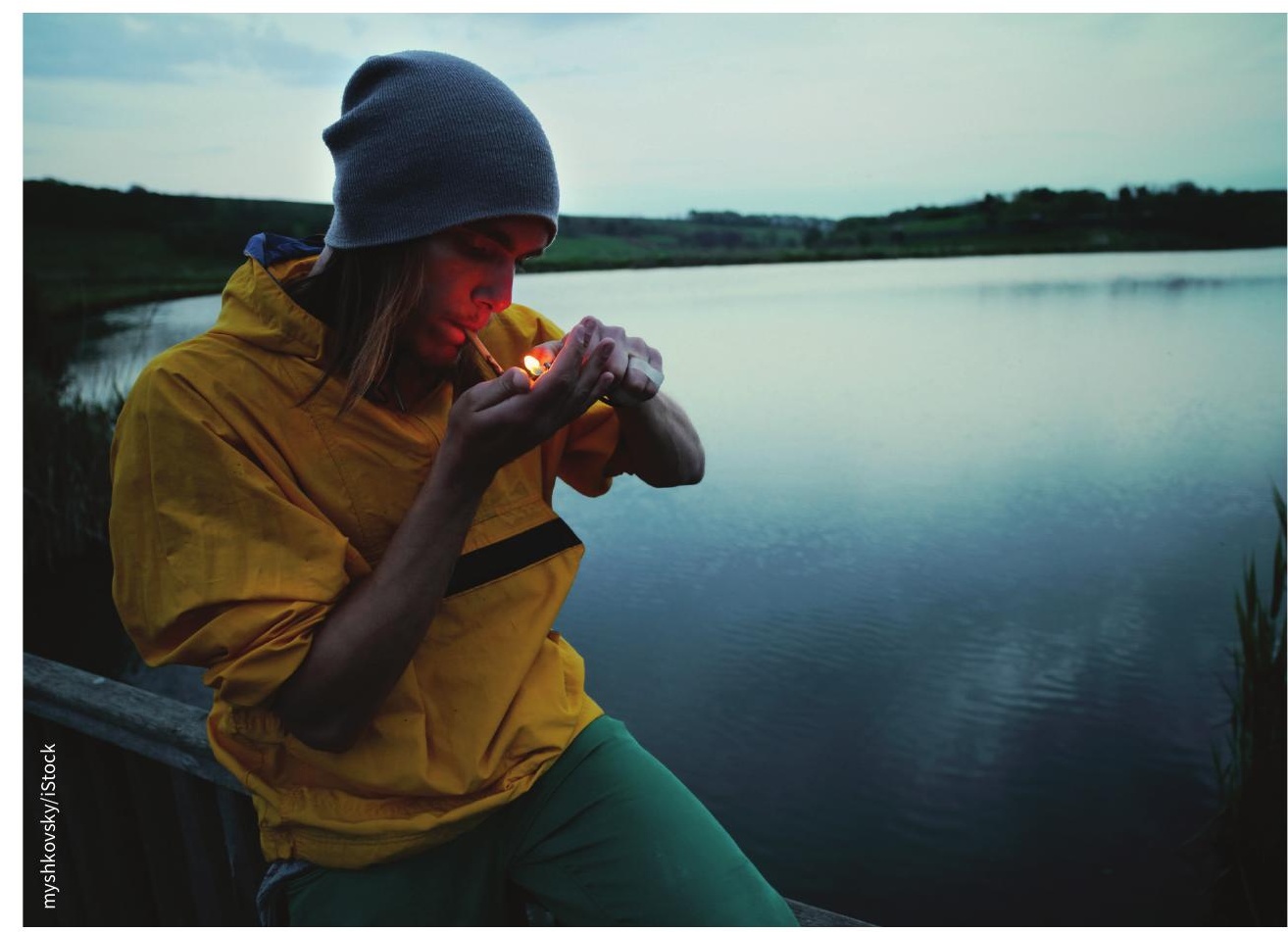

Urgent need for federal investment in research on cannabis health impacts, say researchers.

The task force's call for more research came after consultations with scientists, policy-makers from Health Canada, and experts from the Canadian Centre on Substance Use and Addiction (CCSA), and the Canadian Institutes of Health Research (CIHR). The CCSA released a summary report outlining a national research agenda on the health impacts of nonmedical cannabis use.

This report also recommended that the government dedicate a portion of cannabis tax revenue to health research. "While the specific percentage to be dedicated needs to be determined, a minimum figure of $10 \%$ resonated with the group as a preliminary estimate," stated the report. "There is a pressing need for access to evidence on the health-related effects of non-medical cannabis to best inform policy decisions."

Among the areas requiring study are the linkages between youth usage and mental health problems, the dynamics of cannabis impairment, how to communicate health risks, and the impacts on pregnancy.

CIHR spokesman David Couillard said the CIHR allocated \$1.4 million last summer for short-term projects in areas including cannabis and driving, workplace usage, impact on youth, regulatory impacts, data collection, pregnancy outcomes and second-hand smoke. 
Meanwhile, Health Canada has made efforts to streamline the legal process for cannabis research and gain information about "the knowledge, attitudes and behaviours of Canadians who use cannabis for non-medical and medical purposes" from a survey, according to spokesperson Tammy Jarbeau.

The CCSA has cohosted a symposium on impaired driving, conducted youth focus groups to help create a communication guide, and has been involved in a project aimed at analyzing hospital data to better understand the health impacts of cannabis.

"Funding research is not a trivial task," said Ware. "To some extent, I'm satisfied the urgency has been heard and the responses are beginning to emerge."

But according to Michael DeVillaer of McMaster University, an expert on the epidemiology of drug problems and drug policy, the federal government's hesitation to devote more funding to cannabis research may stem in part from a reluctance to find evidence of harm from a product that produces so much tax revenue.

"We'd hope they would put their responsibilities to support public health research over their hunger for revenue," he said. "But research just doesn't ever seem to have been part of the government's agenda."

Paul Webster, Toronto, Ont. 